\title{
Material and Technological Aspects while Processing of Selected Ultra High Strength Steel
}

\author{
Igor Barényi ${ }^{1}$, Jozef Majerík ${ }^{1}$, Ján Bezecný ${ }^{1}$, Michal Krbat'a ${ }^{1}$, Josef Sedlák ${ }^{2}$, Aleš Jaroš² \\ ${ }^{1}$ Faculty of Special Technology Alexander Dubcek University of Trencin. Pri Parku 19, 91105 Trenčín. Slovak Republic. \\ E-mail: igor.barenyi@nuni.sk,jozef.majerik@tnuni.sk,jan.bezecny@tnuni.sk,michal.krbata@tnuni.sk \\ ${ }^{2}$ Faculty of Mechanical Engineering, Brno University of Technology.Technická 2896/2, 61669 Brno, Czech Republic, \\ E-mail: sedlak@fme.vutbr.cz,jaros.a@fme.vutbr.cz
}

This authors presented article deals with the size of heat affected zone (HAZ) at specific technological processes (cutting and welding techniques). Armox 500 steel was selected and used to perform all realized experiments. Even before the start of the experiments that investigated the effect of HAZ on cutting and welding, it was necessary to subject the investigated Armox 500 steel to basic experimental measurements with regard to its chemical composition, fundamental microstructure and mechanical properties. The microstructure was performed on Neophot 32 optical microscope. Chemical composition was analysed on the spectral analyzer Spectrolab Jr CCD. Mechanical properties, like nanohardness $H$ and reduced Young modulus $E_{r}$ were subsequently measured on Hysitron TI950 Triboindenter with a Cube Corner measuring tip, and evaluated by software Triboscan. Based on the measured values, a 2D nanostructure of the distribution map of $s H$ and $E_{r}$ was evaluated in Matlab. This scientific research, together with all measured and calculated results, is the fundamental that will help to optimizing the quality and used all these results to optimize presented material and technological processes.

Keywords: Armox 500 steel, mechanical properties, microstructure, cutting, welding

\section{Introduction}

Hard steel Armox 500 belongs between the ultra-high strength martensitic steel used as an armor material and protection for special types of vehicles, mobile containers and other special components in armament as well as for the civil exploitations. Ballistic resistances of this material are given through the combination of hardness and strength with optimal value of toughness with respect to the materials characteristics. Armox 500 steel was industrially applied in Slovak Republic for the construction of the Aligator vehicle frame, Bozena demining system or mobile army containers for modular communication system Mokys.

Scientific research together with the development in manufacturing of those types of steels allows decreasing active thickness of armor on $50 \%$ with equal ballistic resistance [7]. Cutting and welding experiments are targeted to study of the affection of the steel by heat and consequently the degradation of basic mechanical properties during application of these processes. Vicker's microhardness courses (HV5) were measured in cross section to the surface after cutting and through welding joints after two welding processes. The Armox steels are group of armoured middle alloyed steels with martensitic structure, heat treated on very high strength and hardness as well as good toughness. These properties result from specific production process of the steel where most important steps are minimizing of $\mathrm{H}, \mathrm{N}$ and $\mathrm{O}$ content by the vacuum furnace and heat treatment consist of quenching with very rapid cooling and low tempering at temperatures about $150 \div 200{ }^{\circ} \mathrm{C}$. If the final steel is exposed to the temperature above the $200^{\circ} \mathrm{C}$ some phase transformations take place in the microstructure and the degradation of mechanical properties needed for the steel usage occurs. These conditions are typical for secondary processing of the steel as are cutting or welding.

\section{Materials and methods}

In this article, all realized experimental investigations were carried out by cutting and welding technological process with respect to chemical compositions, mechanical properties and microstructure of workpiece material, which is Armox 500 steel. Armox steels production technology consists of few significant steps to achieve their desired mechanical properties. First point is a continuous casting process of slab with using of steel of high chemical purity with minor hydrogen level mainly. The next point is the controlled rolling of the slabs at high temperature about $1250{ }^{\circ} \mathrm{C}$ to refine austenitic grains. Then the plates are solution annealed at temperature about $850{ }^{\circ} \mathrm{C}$. Most significant for result high strength and hardness are two final points - quenching and tempering. The plates are quenched in continuous furnace from the temperature about $1000^{\circ} \mathrm{C}$ with very rapid coolant in the water to harden the steels and then finally low tempered at about $200{ }^{\circ} \mathrm{C}$ in order to make hardened steels tougher [2, 3].

The microstructure resulting from this treatment is fine tempered martensite. The producer of Armox steels recommend their secondary processing (machining, cutting, welding etc.) at lower temperatures than tempering temperature due to accidental over tempering and degradation of mechanical properties in heat affected zone. Specific properties of Armox steels demand special tools for secondary treatment of Armox steels by machining. As a result of very high surface hardness, and that's why to high wear of used cutting tool, the cutting edge made by cemented carbide and coated by PVD nano AlTiCN+TiN coating is required to machine Armox 500.

Middle class of Armox high strength steels - Armox 500 was selected as experimental workpiece material. Its fundamental mechanical properties can be seen in Table 2 and chemical composition is disclosed in the Table 1 . Indicated mechanical properties were assessed by the 
standard tensile strength test (EN ISO 6892-1), Charpy impact test (EN ISO 148-1) and Brinell hardness test (EN ISO 6506-1) [6]. Chemical composition was measured by the spectral analyzer Spectrolab Jr CCD. Fundamental microstructure of this steel can be seen in Fig. 1. The in- vestigated microstructure consists of the tempered martensite with assumed small quantity of retained austenite. There are observed some carbides as a product of tetragonal martensite transformation to cubic tempered martensite during tempering.

Tab. 1 Chemical composition of examined steel Armox 500

\begin{tabular}{|c|c|c|c|c|c|c|c|c|c|}
\hline $\begin{array}{c}\text { Chemical composition } \\
\text { [wt. \%] }\end{array}$ & $\mathrm{C}$ & $\mathrm{Si}$ & $\mathrm{Mn}$ & $\mathrm{P}$ & $\mathrm{S}$ & $\mathrm{Cr}$ & $\mathrm{Ni}$ & $\mathrm{Mo}$ & $\mathrm{B}$ \\
\cline { 2 - 19 } & 0.27 & 0.23 & 1.10 & 0.014 & 0.009 & 0.81 & 1.58 & 0.7 & 0.004 \\
\hline
\end{tabular}

Tab. 2 Mechanical properties of examined steel Armox 500

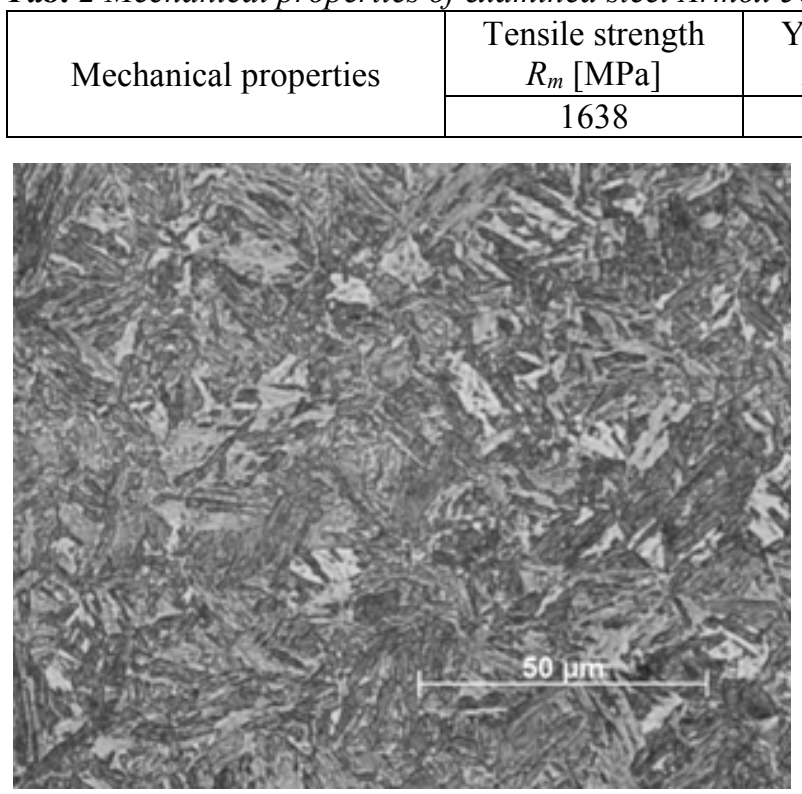

Fig. 1 Microstructure of material Armox 500, etch. Nital (1000x)

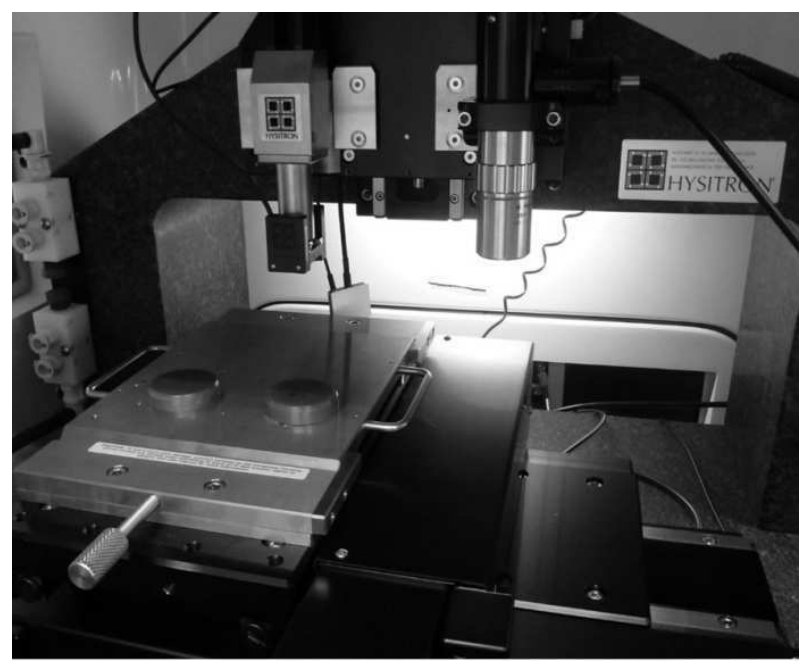

Fig. 2 Selected positions of the measured specimens in the Hysitron TI 950 Triboindenter

The quasistatic nanoindentation measurement method has been conducted in order to investigate mechanical properties of Atmox 500 steel. Hardness and Young modulus were realized by the nanoindentation measuring device TI 950 Triboindenter (directly from the company Bruker Ltd.) in the CEDITEK Laboratory (Center for testing quality and diagnostic of materials) of Mechanical testing in Trencin (Faculty of special technology). In this part of author's research, these realized measurements

\begin{tabular}{|c|c|c|c|}
$R_{p 0.2}[\mathrm{MPa}]$ & $\begin{array}{c}\text { Toughness } \\
K C U[\mathrm{~J}]\end{array}$ & $\begin{array}{c}\text { Hardness } \\
{[\mathrm{HBW}]}\end{array}$ & $\begin{array}{c}\text { Elongation } \\
A_{5}[\%]\end{array}$ \\
\hline 1422 & 25 & 516 & 9 \\
\hline
\end{tabular}

and number of tests were conducted by the quasi static nanoindentation techniques, which fundamental setting of measured specimen can be seen in Fig. 2.

Thermal processed as are plasma or laser cutting are most usually used to cut high strength steels with martensite microstructure. These processes have several benefits as are relative low-cost realization, high cut speed, good quality of cut face etc $[4,10]$. However, there is high risk of overtempering and consequently the degradation of key mechanical properties can occur in affected areas. The reason is the heat input transferred to the cut face during cutting.

The weldability of Armox 500 steel by the conventional arc welding processes is considered as fair whereby its carbon equivalent is $c_{E}=0,46 \div 0,5$. The weld with good quality and utility properties could be done with suitable consumable material and technological precautions as are preheating and post-heating. However, conflicting requirements exist in choosing of proper consumable material for welding of ultra-high strength steel. On the one hand one of general welding says to choose consumable with properties close to base material, but on the other hand high strength steels are very susceptible on cracking during welding and require more ductile consumable to minimize the effect. Therefore, the weakest part of the weld is area of a weld metal almost fully containing consumable material having low mechanical properties in comparison to base high strength steel.

\section{Results and discusssion}

The quasistatic nanoindentation analysis is focused on main microstructure parts revealed through microstructure study by the optic microscopy. The displacement $(h)$ is monitored as a function of the load $(P)$ throughout the load-unload cycle where resulting relation $P-h$ is called nanoindentation curve. However, elastic plastic contact occurs in real materials. There are both plastic and elastic deformations during indentation test on examined material surface. Plastic part of deformation is typically used to determine Young's Modulus, while the elastic-plastic part both with indent surface is used to evaluate the nanohardness $H$. The selected areas of the specimen surface area were scanned by the SPM (Scanning probe microscopy) technique with using nanoindentation probe first (of the type Cube Corner, which is optimal geometry for the high strength materials testing). In the next 
step, the quasistatic nanoindentation process was performed on selected location in the SPM image.

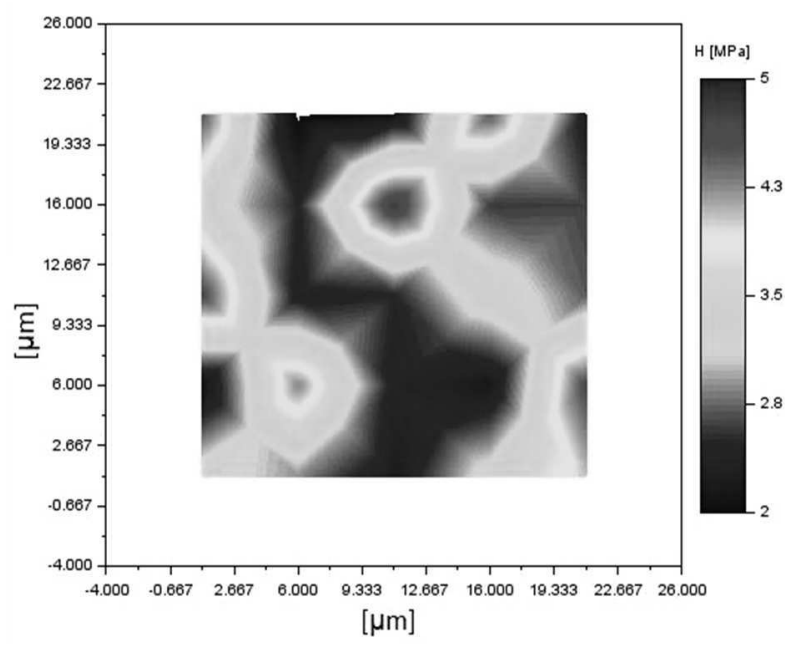

Fig. 3 The SPM image of Armox 500 particles with nanoindentation pattern (both $25 \times 25 \mu \mathrm{m}$ ), statistical processed $2 D$ map of nanohardness $H$ [GPa] directly from measured values

Based on the results from optical microscopy, it has shown that the Armox 500 high-strength microstructure is fine-grained and consists of martensitic and assumed small residual austenite. Based on this fact, the rectangular pattern was $25 \times 25 \mu \mathrm{m}$ with a regular spread of puncture nut $5 \times 5$. The distances between the inches in both directions were $5 \mu \mathrm{m}$. Based on the measured values obtained from individual inches, a 2D nanostructure of the distribution map of nanohardness $H$ (can be seen in Figure 3 ) and a reduced modulus of elasticity $E_{r}$ (can be seen in Figure 4) was processed in the Matlab system. Used quasistatic nanoindentation measuring device uses the SPM to visualise measured area where nanoindentation tip oscillate and tapping over the area. Moreover, the quasistatic nanoindentation allows to measure local mechanical properties of these material structure constituents.

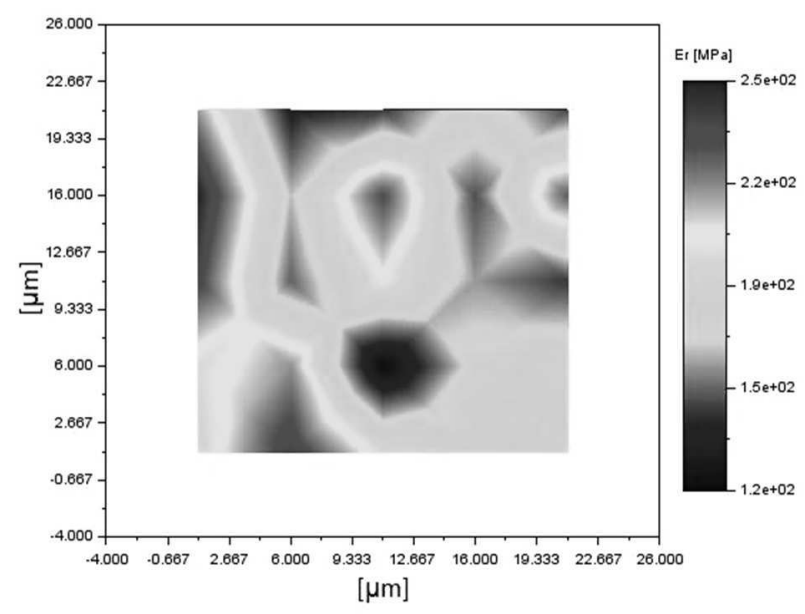

Fig. 4 The SPM image of Armox 500 particles with nanoindentation pattern (both $25 \times 25 \mu \mathrm{m}$ ) statistical processed 2D map of reduced Young modulus $E_{r}$ directly from measured values

We perform the experiment to determine the decrease of hardness in the HAZ (heat affected zone) after cutting the high strength steel by two thermal processes. The objects of experiment are samples of Armox 500 steel with the HAZ after cutting by laser and plasma. The basic parameters of both used processes can be seen in Table 3 and Table 4. Heat affected zones after application of these thermal processes were evaluated by microhardness Vicker's test (HV0,5) on samples made of Armox 500 steel with three different thickness $t=4,5$ and $8 \mathrm{~mm}$. These samples were measured to determine the microhardness profile in cross section to the cut face and describe the changes in hardness values after affecting the material by heat during cutting process.

Tab. 3 Basic parameters of used laser cutting process

\begin{tabular}{|c|c|c|c|}
\hline Thickness $[\mathrm{mm}]$ & Laser Output $[\mathrm{W}]$ & Frequency $[\mathrm{Hz}]$ & Cutting speed $\left[\mathrm{m} . \mathrm{min}^{-1}\right]$ \\
\hline 4 & 1900 & 10000 & 3.1 \\
\hline 5 & 3200 & 10000 & 2.9 \\
\hline 8 & 3200 & 10000 & 2.9 \\
\hline
\end{tabular}

Tab. 4 Basic parameters of used plasma cutting process

\begin{tabular}{|c|c|c|c|c|}
\hline Thickness $[\mathrm{mm}]$ & Voltage $[\mathrm{V}]$ & Current $[\mathrm{A}]$ & Cutting speed $\left[\mathrm{m}_{\mathrm{min}} \mathrm{m}^{-1}\right]$ & \multirow{2}{*}{ Plasma gas: O2 } \\
\cline { 1 - 4 } 4 & 120 & 30 & 0.9 & \multirow{2}{*}{ Supplementary gas: O2 / N2 } \\
\hline 5 & 125 & 45 & 0.85 & 0.55 \\
\hline 8 & 130 & 50 & & \\
\hline
\end{tabular}

The course of microhardness in cross section to the cut face for Armox 500 steel with thickness $5 \mathrm{~mm}$ cut by plasma and laser is in Fig. 5.

Three characteristic different areas of the HAZ are recognizable in the course of microhardness:

- increase of hardness in narrow area close under the cut face (heating up to the temperature in austenite area and rapid cooling),
- intensive decrease of hardness (uncontrolled tempering of origin martensitic structure),

- slow increase of microhardness to the value of base material hardness.

As is evident from the course, heat affection is more noticeable in plasma cutting process. Same character of heat affection is resulted from the values of depth of the 
HAZ after cutting can be seen in Table 5. Depth of the HAZ is evaluated by adapted method commonly used for evaluation of layers after application of surface hardening processes based on limit hardness as a criterion for reading the depth value from hardness course $[9,11]$.

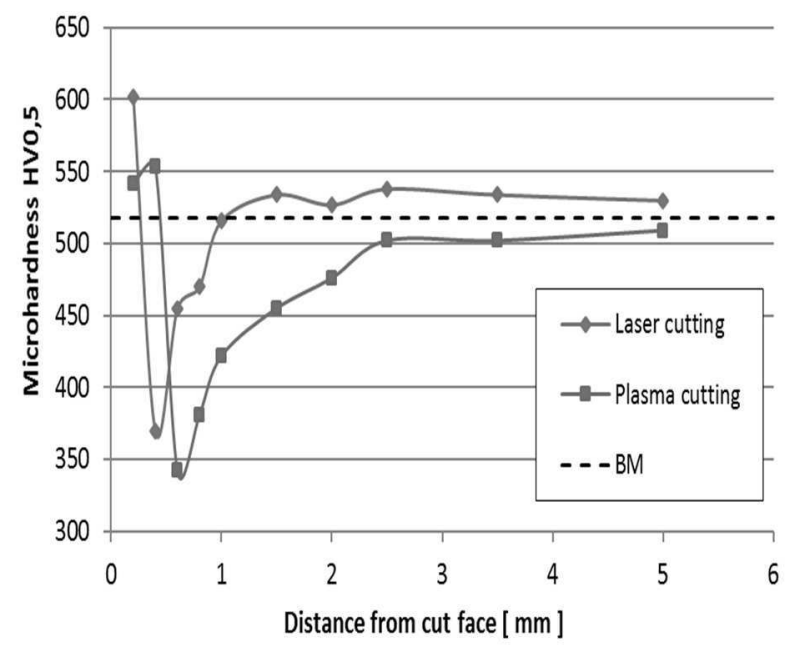

Fig. 5 Course of microhardness in cross section to the cut face for Armox 500 with $t=5 \mathrm{~mm}$ cut by plasma and laser

Moreover, the part of hardness courses where the hardness slowly increases is used only for depth of HAZ evaluating. The hardness of base material is considered as the limit hardness. The values of the depths of the HAZ also varying in dependency on material thickness as are shown in Table 5. Depth of the HAZ is noticeably higher for thickness $t=8 \mathrm{~mm}$. The reason is in using of different process parameters for different thickness of cut material.

Tab. 5 Depths of the HAZ for laser and plasma cutting on Armox 500 sample

\begin{tabular}{|c|c|c|}
\hline \multirow{2}{*}{ Thickness $t[\mathrm{~mm}]$} & \multicolumn{2}{|c|}{ Depth of heat affected zone $[\mathrm{mm}]$} \\
\cline { 2 - 3 } & Laser cutting & Plasma cutting \\
\hline 4 & 0.77 & 2.40 \\
\hline 5 & 1.06 & 2.53 \\
\hline 8 & 3.25 & 3.90 \\
\hline
\end{tabular}

Other serious problem in welding of ultra-high strength steels is their overtempering during the process and the large width of the HAZ $[1,5,8]$. We perform two experiments to study the welding aspects of Armox 500. The purpose of first experiment is to determine the degradation of mechanical properties in the HAZ after the conventional MAG (Metal Active Gas) welding. Used basic parameters for the MAG welding are shown in Table 6.

Second experiment is targeted to verification of welding possibility of high strength steel by the FSW (Friction Stir Welding). The FSW could be a suitable replacement of conventional arc welding methods for ultra-high strength steel with noticeably lover affection by heat input. Used basic parameters for the FSW are shown in Table 7.

Tab. 6 Basic welding parameters of the used MAG method

\begin{tabular}{|c|c|c|c|c|c|}
\hline $\begin{array}{c}\text { Current } \\
{[\mathrm{A}]}\end{array}$ & $\begin{array}{c}\text { Voltage } \\
{[\mathrm{V}]}\end{array}$ & Polarity & $\begin{array}{c}\text { Wire feed } \\
\text { rate }\left[\mathrm{m} \cdot \mathrm{min}^{-1}\right]\end{array}$ & Filler material & $\begin{array}{c}\text { Protective } \\
\text { atmosphere }\end{array}$ \\
\hline $145 \div 155$ & $27-29$ & $=(+)$ & $15 \div 6$ & Thermanit $\mathrm{X}$ & $80 \% \mathrm{Ar}^{2} 20 \% \mathrm{CO}_{2}$ \\
\hline
\end{tabular}

Tab. 7 Basic welding parameters of the used FSW method

\begin{tabular}{|c|c|c|c|}
\hline $\begin{array}{c}\text { Tool rotation speed } \\
{\left[\mathrm{min}^{-1}\right]}\end{array}$ & $\begin{array}{c}\text { Advance of tool } \\
{\left[\mathrm{mm} \cdot \mathrm{min}^{-1}\right]}\end{array}$ & $\begin{array}{c}\text { Inclination of tool } \\
{\left[{ }^{\circ}\right]}\end{array}$ & $\begin{array}{c}\text { Depth of tool absorption to } \\
\text { material [mm] }\end{array}$ \\
\hline 400 & 50 & 3 & $0 \div 0.1$ \\
\hline
\end{tabular}

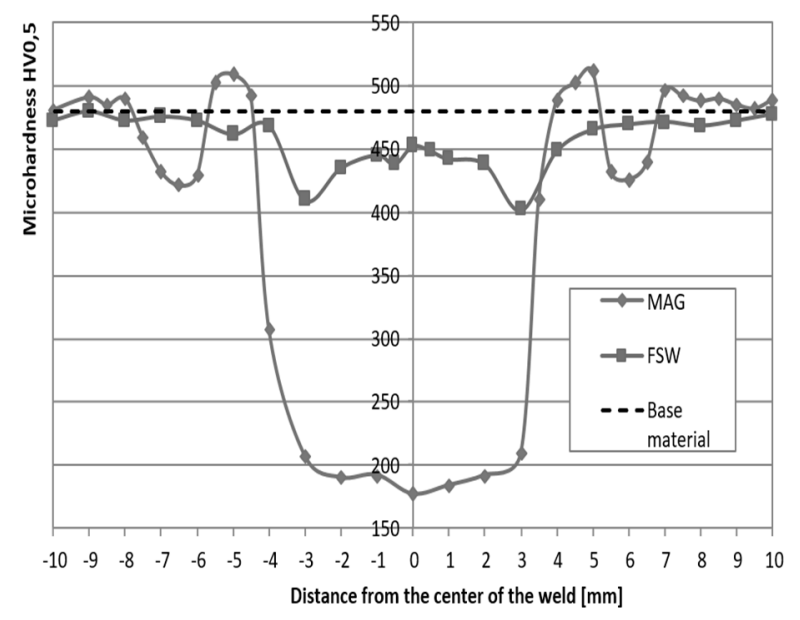

Fig. 6 Course of microhardness across the weld joint of Armox 500 steel made by the MAG and the FSW welding
There is shown course of microhardness across the weld joint of Armox 500 steel made by the MAG welding technology in Fig. 6 (blue curve). Some characteristic areas of welding joint are noticeable in the course in order from the weld center. Central zone with highest decrease of microhardness is wide $5 \div 6 \mathrm{~mm}$ and is almost filled with consumable material only. Mechanical properties of this part correspond to used consumable properties and not to base material as was stated above and is not considered as a part of heat affected zone. Next characteristic zone in the course is the area with increased hardness above the value of base material hardness. This is the area with full recrystallization and consequent repeard martensitic transformation what results to the high hard but relatively brittle martensitic needle structure. The wide of this area is relatively narrow $(1 \div 1,5 \mathrm{~mm})$. The last area with rapid decreasing of nanohardness, and then its slow increasing to the value of base material hardness which corresponding with uncontrolled tempering area). Relative 
decrease of hardness in this area is about $30 \%$ in comparison to the base material hardness.

The red curve in Fig. 6 represents the course of microhardness through weld joint made by the FSW (Friction Stir Welding) with using of the same high strength steel. The FSW is a solid-state joining process where is not required to use consumable material. Weld joint is made by rotating pin tool whereby the tool is loaded by extreme force. Welding heat is generated by friction between the rotating tool and the workpiece material, which leads to a plasticized softened region near the FSW tool. Course of microhardness through joint made by FSW is without weld metal zone with very low hardness. Some hardening effect due to influence of welding pin to the material is present in the center of the weld. However, this hardening does not reach the values of hardness of original base material. The area in the center of the weld is the mixed zone with strong thermomechanical effect including weld nugget. Despite of the TMS effect presence, the microhardness course for Armox 500 is decreasing in this area. Thermal part of the affection in this area causes microstructure change in comparison to the base material. Study of microstructure also confirms partial recrystallization in this area due to high temperature. Next to this area lies the TMS influenced zone where are both thermal and mechanical affection still present. However, the temperature and the deformation are considerably lower in comparison to mixed area with the nugget. The deformation part of the influence causes small increase in hardness values.

\section{Conclusion}

The processing of the ultrahigh strength martensitic steels Armox with using the processes based on thermal transfer causes the formation of significant heat affected zone. The width of the HAZ depends on heat input brought to the processed material which is a function of specific welding or cutting parameters.

Conclusions found by HAZ study of cut faces after laser and plasma cutting of Armox 500 steels could be summarizing to the following points:

- Depth of measured HAZ by plasma cutting faces is significantly bigger in comparison to the laser cutting. For example, the HAZ reaches $20 \%$ of total thickness of cut material $(5 \mathrm{~mm})$ for laser cutting and almost $50 \%$ for plasma cutting.

- In respect to the cut thickness, depth of HAZ increases in relation to the thickness of the material. Thick material requires higher heat unput to be fully cut.

- As a result, the HAZ is almost as wide for both technologies in a case of higher thickness ( 8 $\mathrm{mm})$. In a case of $h=8 \mathrm{HAZ}$ reaches $65 \%$ of total thickenss for laser cutting and $80 \%$ for plasma cutting.

Described influence may affect final quality of processed product with smaller intersections mainly. Due to these reasons is advisable to cut Armox materials by using of the water jet cutting process which is without the heat affection in principle.

Welding of Armox is more problematic because the heat transfer is much bigger than in cutting processes where its amount is essential to make enough quality weld joint by conventional welding methods as MAG is. Most weaken part of MAG weld joint is the weld metal as a mixture of base material and consumable material. Optimizing of welding parameters considering heat input could help to minimize heat affection. Also, some progressive welding method could be used besides conventional arc welding methods as is friction stir welding that using lower welding temperatures. Structure of weld joint made by the FSW is different from the conventional MAG welding as results from the comparison of the microhardness courses for the MAG and the FSW which can be seen in Fig. 6. As is apparent from the FSW principle, joint made by this method does not consist consumable material and morover thermo mechanical effect may occur in it with possible increasing of mechanical properties values. However, this strengthening does not occurs or is very low and did not appear in the microhardness curve of the FSW joint of Armox 500 steel. Nevertheless, the experimental results confirm that it is possible to weld of Armox steel with high hardness and strength by FSW method to form a better joint than with conventional welding methods. Limiting factor of technological realisation is the need of special very hard weld tool because of high hardness of the steel.

\section{Acknowledgement}

This work was supported by the Slovak Research and Development Agency under the contract No. APVV-150710 and also was supported by the BUT, Faculty of Mechanical Engineering, Brno, Specific research 2016, with the grant "Research of modern production technologies for specific applications", FSI-S-16-3717.

\section{References}

[1] BELHADJ, A., BAUDOUIN, P., HOUBAERT, Y. (2002). Simulation of the HAZ and magnetic properties of laser cut non-oriented electrical steels. In: Journal of Magnetism and Magnetic materials, Vol. 248, Issue. 1, pp. 33 - 34.

[2] BARÉNYI, I. (2016). Microstructure changes in cut face obtained by plasma and laser cutting of selected high strength steels. In: IPB Scientific Bulletin, Series D: Mechanical Engineering, Vol. 78, Issue 1, pp. 233 - 240.

[3] BARÉNYI, I. (2018). Study of heat affected zone after cutting and welding of armoured ultra-high strength steels. In: Manufacturing Technology, Vol. 18, Issue 2, pp. 185 - 189.

[4] BØRVIK, T., DEY, S., CLAUSEN, A. H. (2009). Perforation resistance of five different high-stren- 
gth steel plates subjected to small-arms projectiles. In: International Journal of Impact Engineering, Vol. 36, Issue 7, pp. 948 - 964.

[5] JANICKI, D. (2014). Disk laser welding of armor steel. In: Archives of Metallurgy and Materials, Vol. 59, Issue. 4, pp. 1641 - 1646.

[6] LIM, H. S., LEE, J., SONG, Y. B., KIM, H. K., HWANG, B. (2017). Effect of tempering temperature on the microstructure and mechanical properties of Armox 500T armor plate. In: Korean Journal of Materials research, Vol. 27, Issue. 7, pp. $357-361$.

[7] POSPÍCHAL, M., DVORÁKOVÁ, R., STUDENÝ, Z., POKORNÝ, Z. (2015). Influence of initial carbon concentration of nitride layers. In: Manufacturing Technology, Vol. 15, Issue 5, pp. $889-893$.

[8] RAGU NATHAN, S., BALASUBRAMANIAN, V., MALARVIZHI, S., RAO, A. G. (2015). Effect of welding processes on mechanical and microstructural characteristics of high strength low alloynaval grade steel joints. In: Defence Technology, Vol. 11, Issue. 3, pp. $308-317$.

[9] SIVARAMAN, V., SANKARAN, S., VIJAYARAGHAVAN, L. (2015). A study on the influence of cutting parameters on forces during machining the multiphase V-microalloyed steel. In: International Journal of Advanced Manufacturing Technology, Vol. 79, Issue 5-8, pp. 1285 - 1292.

[10] STUDENÝ, Z., DOBROCKÝ, D., POKORNÝ, Z. (2017). Importance of diffusion process on the fatigue life of steel. In: Manufacturing Technology, Vol. 17, Issue 1, pp. $94-99$.

[11] VAN DOAN, T., KUSMIČ, D., POSPÍCHAL, M., TRAN, D. Q. (2017). Friction and wear behaviour of $42 \mathrm{CrMo} 4$ steel treated by tenifer hard chorme and plasma nitriding Technologies. In: Manufacturing Technology, Vol. 17, Issue 2, pp. $168-174$. 